\title{
Technical requirements for entries in flameproof enclosures operating in potentially explosive atmospheres
}

\author{
Marcel Daniel Rad", Dragos Fotau, and Sorin Zsido \\ National Institute for Research and Development in Mine Safety and Protection to Explosion - \\ INSEMEX, 32-34 G-ral Vasile Milea, 332047, Petrosani, Hunedoara, Romania
}

\begin{abstract}
The evaluation of explosion-proof electrical equipment for certification is particularly important given the risk of explosion and must be minimized. This in order to ensure the safety of life, health of workers, to prevent damage to goods and the environment when they meet the essential security requirements at European level. Directive 2014/34 / EU states that equipment used in explosive atmospheres must be designed to operate without endangering the environment for which it is intended. This paper proposes the study and evaluation of the requirements for flameproof enclosures. In order to verify explosion protection, the representative samples made available by explosion-protected equipment manufacturers are tested under the worst possible conditions that may occur in practice.
\end{abstract}

\section{Introduction}

This paper deals with the analysis of explosion protection characteristics for the flameproof enclosures cable entries. Several studies were made on the reliability of electrical equipment and installations.

Types of protection represents all the specific measures that are applied to electrical equipment in order to avoid the ignition of the explosive atmosphere surrounding the equipment.

According to Directive 1999/92/EC, the users of technological installations operating in areas with hazard of explosive atmospheres must follow successively three stages: prevention of forming the explosive atmospheres, avoidance of igniting the explosive atmospheres, limitation of harmful effects in case of an explosion in order to ensure and preserve the health and safety of workers (Directive 1999/92/EC, 1999).[1]

According to IEC 60079-1/2014, the flameproof characteristics of the enclosure are not altered if all entries meet the specific requirements given in this clause and shall be one of the following:

-internal metric threads with a class of tolerance of $6 \mathrm{H}$ (or better) according to ISO 965 1 and ISO 965-3, and any chamfer or undercut is limited to a maximum depth of $2 \mathrm{~mm}$ from the external wall surface;

\footnotetext{
* Corresponding author: marcel.rad@insemex.ro
} 
-external metric threads with a threaded part of at least $8 \mathrm{~mm}$ in length and at least eight full threads. If the thread is provided with an undercut, then a non-detachable and noncompressible washer or equivalent device shall be fitted to ensure the required length of thread engagement;

-internal NPT threads;

-external NPT threads;

-for Group I applications only, non-threaded joint.[2]

The requirement for at least eight full threads is to ensure that at least five full threads will be engaged when the part is installed in a threaded entry, taking into account the presence of any chamfer or undercut.

This requirement is not intended to apply to integral cable glands or similar entry devices provided, as an enclosure part, by the manufacturer.

\section{Generalities regarding the entries for flameproof enclosures}

The main elements that are part of the entries for flameproof enclosures are:

-threaded holes in enclosures;

-non-threaded holes;

-cable glands;

-conduit sealing devices;

-plugs and sockets and cable couples;

-bushings;

-blanking elements.

\subsection{Threaded holes}

Threaded holes in enclosures, performed to facilitate cable glands (or conduit entries) shall have the type of thread and size identified (e.g. M25 or 1/2NPT). This can be made by

-marking of the specific thread type and size adjacent to the hole;

-marking of the specific thread type and size on the nameplate;

-identification of the specific thread type and size as part of the installation instruction document, with a reference marking on the nameplate.[2]

The manufacturer shall state the following in the documents defining the electrical equipment:

a) the places where entries can be fitted; and

b) the maximum permitted number of these entries.

Entries must not have more than one thread adapter in case an adapter is used. It is not admitted to use a blanking element with an adapter.[3]

\subsection{Non-threaded holes}

For Group I only, plain (non-threaded) holes to facilitate the installation of cable glands or bushings shall state the following in the documents defining the electrical equipment:

-minimum width of joint " $L$ " and maximum gap for flanged, cylindrical or spigot joint; -mounting stud or bolt specifications (such as diameter, thread, tensile strength, length, head type, torque) and position (such as pitch circle diameter and spacing);

-keeper plate, and associated fastener(s), dimension requirements and position (such as quantity, spacing of the holes to support the gland, diameter, coupling means);

-minimum tensile strength requirement of materials, fasteners;

-maximum and minimum thread engagement for the holes in the enclosure; and 
-information that will relate the length of fasteners to thickness of the keeper plate under the fastener head to ensure that the fasteners will have correct engagement and will allow correct space at the bottom of holes.[2]

\subsection{Cable glands}

Cable glands (integral or separate) shall meet the relevant requirements of EN 60079-1.

Where cable glands are integral with the enclosure or specific to the enclosure, they shall be tested as part of the enclosure concerned.[3]

Where cable glands are separate:

a)threaded Ex cable glands and non-threaded Ex cable glands (for Group I only) can be evaluated as equipment. Such cable glands do not have to be submitted to the type tests

b)other cable glands can only be evaluated as an Ex component; and

c) sufficient information shall be provided in the documentation to facilitate the mounting in holes, as applicable.[2]

\subsection{Conduit sealing devices}

Conduit sealing devices, whether integral or separate, shall meet the requirements of this standard with "conduit sealing device" substituted for "cable gland" and create, on the enclosure, the joint widths and gaps.

Where conduit sealing devices are integral with the enclosure or specific to the enclosure, they shall be tested as part of the enclosure concerned.

Where conduit sealing devices are separate:

-threaded Ex conduit sealing devices can be evaluated as equipment. Such conduit sealing devices do not have to be submitted to the type tests;

-other conduit sealing devices can only be evaluated as an Ex component; and

-sufficient information shall be provided in the documentation to facilitate the installation in holes.

Conduit entries are allowed for use only in case of Group II electrical equipment.

A sealing device (a stopping box with setting compound) has to be provided, as part of the flameproof enclosure (or immediately at the entrance thereto). It shall satisfy the type test for sealing. An evaluated sealing device may be applied by the installer or user of the equipment according to instructions provided by the manufacturer of the equipment.

The sealing compound and method of application shall be specified in the certificate either of the stopping box or of the complete flameproof equipment. The part of the stopping box between the sealing compound and the flameproof enclosure shall be treated as a flameproof enclosure.[3]

The distance from the closest face of the seal to the specific enclosure (or the intended end-use enclosure), and the outside wall of the enclosure (or the intended end-use enclosure) must be as small as possible (practical), but it shall not be larger than the conduit size or $50 \mathrm{~mm}$, whichever is the lesser.[4]

\subsection{Plugs and sockets and cable couplers}

If attached on a flameproof enclosure plugs and sockets shall be made and installed so as the flameproof properties of the enclosure (on which they are mounted) are not altered, even when the two parts (of the plugs and sockets) are separated. The widths and the gaps of the flameproof joints of the flameproof enclosures of plugs and sockets and cable couplers shall be determined by the volume which exists at the moment of separation of the contacts other than those for earthing or bonding. For plugs and sockets and cable couplers, 
the flameproof properties of the enclosure shall be maintained in the event of an internal explosion, both when the plugs and sockets or cable couplers are connected together and at the moment of separation of the contacts.[2]

If not connected to an interlocking switch which ensures a time delay between switching of the load and disconnecting the plug and socket, the plug and socket shall remain flameproof during the arc-quenching period while opening a test circuit of the rated voltage and rated current. For a.c. circuits, the test circuit power factor shall be less than or equal to 0,6 , unless the equipment is marked for resistive loads only. [4]

\subsection{Bushings}

Bushings, whether integral or separate, shall meet the requirements of IEC 60079-1 create, on the enclosure, the joint widths and gaps prescribed.

Where bushings are integral with the enclosure or specific to the enclosure, they shall be tested as part of the enclosure concerned.

Where bushings are separate:

-threaded Ex bushings for Group I or II, and non-threaded Ex bushings for Group I, can be evaluated as equipment. Such bushings do not have to be submitted to the type tests; -other bushings can only be evaluated as an Ex component; and

-sufficient information shall be provided in the documentation to facilitate the mounting in holes.[3]

\subsection{Blanking elements}

If, at the determination of the manufacturer, entries provided in a flameproof enclosure are not intended to always be used, they shall be closed by Ex equipment or Ex component blanking elements so that the flameproof properties of the enclosure are maintained.

Ex component blanking elements are only suitable when specified as part of the Ex equipment certificate. A blanking element shall not be used with a thread adapter. Sufficient information shall be provided in the documentation to facilitate the mounting in holes.[2]

\section{Verification and tests}

The requirements of IEC 60079-0 concerning verification and testing are, for the type of protection flameproof enclosure " $\mathrm{d}$ ", supplemented by the following requirements.

The determination of the maximum surface temperature specified in IEC 60079-0 shall be made under the conditions defined in IEC 60079-1.[3]

The type tests shall be carried out in the following sequence:

-determination of the explosion pressure (reference pressure) on one sample that may or may not have been subjected to the tests of enclosures in accordance with IEC 60079-0; -overpressure test on one of the samples which has been subjected to the tests of enclosures in accordance with IEC 60079-0; and

-test for non-transmission of an internal ignition on one sample that may or may not have been subjected to the tests of enclosures in accordance with IEC 60079-0 and may or may not have been subjected to the test from above.[3]

Testing may deviate from this sequence in that the static or dynamic overpressure test may be carried out either after the test for non-transmission of an internal ignition or on another sample which has also been subjected to those other tests affecting mechanical strength already applied to the first sample.[2] 


\section{Cable glands and conduit sealing devices with sealing ring}

These tests shall be carried out using, for each type of cable gland or conduit sealing device, one sealing ring from each of the different permitted sizes. In the case of elastomeric sealing rings, each ring is mounted on a clean, dry, polished corrosion-resistant metals (such as 316 stainless steel) cylindrical mandrel of diameter, equal to the smallest cable diameter permissible in the ring, as specified by the manufacturer of the cable gland or conduit sealing device.[5]

In the case of metallic or composite sealing rings, each ring is mounted on the metal sheath of a clean dry sample of cable, of diameter equal to the smallest diameter permissible in the ring, as specified by the manufacturer of the cable gland or conduit sealing device.

In the case of sealing rings for non-circular cables, each ring is mounted on a clean dry sample of cable, of perimeter equal to the smallest value permitted in the ring, as specified by the manufacturer of the cable gland or conduit sealing device.

The assembly is then fitted into the entry and a torque is applied to the screws (in the case of a flanged compression device) or to the nut (in the case of a screwed compression device) to obtain a seal under a hydraulic pressure of $2000 \mathrm{kPa}$ for Group I and $3000 \mathrm{kPa}$ for Group II.[4]

The torque figures referred to in the preceding paragraph are either determined experimentally prior to the tests, or are supplied by the manufacturer of the cable gland or conduit sealing device.

The assembly is then mounted into a hydraulic testing device using coloured water or oil as the liquid, the principle of which is illustrated in Figure 1. The hydraulic circuit is then purged. The hydraulic pressure is then gradually increased.

The sealing is considered satisfactory if the blotting paper is free from any trace of leakage when the pressure has been maintained at $2000 \mathrm{kPa}$ for Group I or $3000 \mathrm{kPa}$ for Group II, for at least $10 \mathrm{~s}$.

In order to maintain the test pressure, it can be necessary to seal all the joints of the cable gland or conduit sealing device mounted in the test device, other than those associated with the sealing ring under test. When a sample of metal-sheathed cable is used, it can be necessary to avoid the application of pressure to the ends of the conductors or to the interior of the cable.[2]

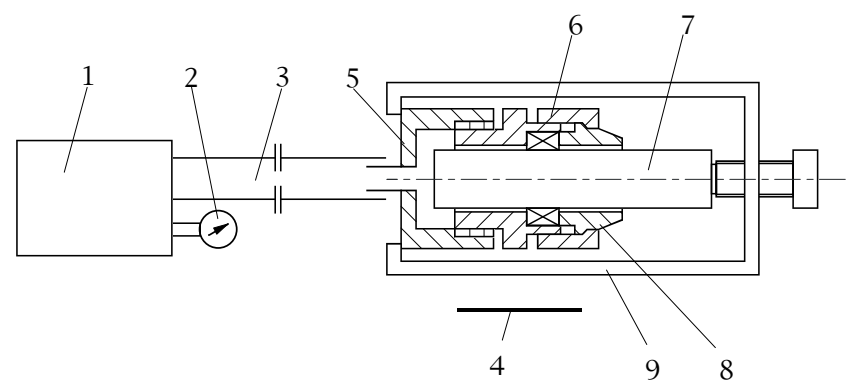

Fig. 1. Device for the sealing tests for cable glands

1-hydraulic pump; 2-pressure gauge; 3-hose; 4-blotting paper; 5-adapter; 6-sealing ring;

7-mandrel/metal-sheathed cable; 8-compression component; 9-retaining clamp. 


\section{Conclusion}

The paper aims at studying and assessing the requirements for elements that are part of the entries for flameproof enclosures with types of protection flameproof enclosure Ex d. An analysis has been made of the equipment and components to be purchased.

The verification of the mentioned elements that are part of the entries can be performed in compliance with the requirements of the applicable standards (SR EN 60079-1Protection of the equipment with type of protection flameproof enclosure Ex d, which will increase the capacity of the group testing laboratories to perform tests on equipment with types of protection Ex d, for use in potentially explosive atmospheres.

As a result of the analysis of the developed test technology and the developed methodology, it has been shown that all the requirements imposed by the standard SR EN 60079-0 and SR EN 60079-1 regarding the testing of elements that are part of the entries for flameproof enclosures with types of protection flameproof enclosure Ex d.

The work presented their equipment and their characteristics, which belong to the inspection stand.

The purpose of this paper was to study and analyze the main elements that are part of the entries for flameproof enclosures.

A test procedure has been developed to check the test procedure has been developed to check the elements that are part of the entries for flameproof enclosures.

\section{References}

1. Directive 1999/92/EC (1999)

2. Standard EN 60079-1 (2015)

3. Standard EN 60079-0 (2013)

4. G. Bottril, D. Chueyne, Practical electrical equipment and installations in hazardous areas, Elsevier Publishers,UK 149-150., 2005

5. S. Simion, O. Baron, Explosion Risk, (in Romanian) Europrint Publishing House, Oradea, Romania, 2004 